\title{
Avaliação da capacidade adaptativa (ACI) no município de Santos/SP a partir das mudanças climáticas
}

\author{
Fabiano de Araujo Moreira ${ }^{(a)}$, Luci Hidalgo Nunes ${ }^{(b)}$, José Marengo ${ }^{(c)}$ \\ (a) Departamento de Geografia/UNICAMP, E-mail: fabianoamoreira@yahoo.com.br \\ (b) Departamento de Geografia/UNICAMP, E-mail: luci@ige.unicamp.br \\ (c) CEMADEN, E-mail: jose.marengo@ cemaden.gov.br
}

\section{Eixo: Climatologia em diferentes níveis escalares: Mudanças e variabilidades}

\section{Resumo}

\begin{abstract}
É premente a elaboração de políticas públicas de redução da emissão de gases de efeito estufa e adaptação às mudanças climáticas nas aglomerações urbanas costeiras. Esta pesquisa visa contribuir para a articulação entre os cenários projetados por pesquisas científicas e as decisões políticas no município de Santos, já que as ações municipais por parte dos tomadores de decisão tem se pautado nos problemas imediatos, não incorporando de forma efetiva as previsões de mudanças ambientais desenvolvidas no campo científico. Parte do projeto temático Metropole, (chamada Belmont/Fapesp), tem-se por meta observar se as mudanças climáticas estão efetivamente internalizadas em ações, ou se elas aparecem meramente como um discurso inócuo, sem medidas e que, dessa forma, poderia trazer consequências duradouras e nefastas para esse município. Essa avaliação foi realizada a partir do Índice de Capacidade Adaptativa, aplicado em uma série de agentes que têm por responsabilidade ditar a regulamentação do município, observando como o discurso se traduz, ou não, em ações efetivas para a adaptação municipal face ao advento das mudanças climáticas, em especial, mudanças no nível do mar.
\end{abstract}

Palavras-chave: Mudanças Climáticas; Adaptação; Mitigação; Capacidade Adaptativa.

\section{Introdução}

Com a divulgação do quinto relatório do Painel Internacional Intergovernamental sobre Mudanças Climáticas (IPCC-AR5), em 2013, se mantém a indicação de que a ação humana continua a afetar o balanço de energia na Terra pela emissão de importantes gases de efeito estufa e pela alteração do uso da terra. De acordo com o AR-5, os cenários elaborados nos relatórios passados em relação às concentrações de $\mathrm{CO}_{2}$, temperatura média mundial e nível dos oceanos estão se confirmando, enquanto apenas os níveis de $\mathrm{CH}_{4}$ e $\mathrm{N}_{2} \mathrm{O}$ estão abaixo daqueles previstos.

Desde o relatório anterior (2007) o IPCC apontava a maior concentração de gases de efeito estufa na atmosfera pelos últimos 500.000 anos, que teriam aumentado $70 \%$ apenas nas últimas quatro décadas. Seguindo diversos modelos, as estimativas para o ano de 2100 são de que a temperatura média global em superfície poderá aumentar de $1,1^{\circ} \mathrm{C}$ a $6,4^{\circ} \mathrm{C}$, enquanto o nível médio dos oceanos poderá elevar entre 18 
cm e $59 \mathrm{~cm}$, além de se tornarem mais ácidos. Além disso, também haveria mais extremos positivos de temperaturas e de precipitação pelo mundo.

Analisando o caso do Brasil, Carmo e Silva (2009) alertam que grande parte da população que reside nas aglomerações urbanas litorâneas poderá sofrer, direta ou indiretamente, algum impacto desse fenômeno. Os autores explicam que ainda há grande grau de incertezas em relação aos níveis que essa elevação dos mares pode atingir, já que "a dinâmica dos oceanos envolve uma inter-relação complexa entre fatores como a expansão térmica dos oceanos e o derretimento das calotas polares e das grandes geleiras" (CARMO; SILVA, 2009, p. 140). Dessa forma, os modelos adotados pelos pesquisadores da área resultam em valores que variam bastante, sendo que o mais novo relatório publicado pelo IPCC, AR-5, em 2013, aumentou suas estimativas das cotas máximas possíveis para o aumento dos mares em relação ao relatório de 2007, variando de $17 \mathrm{~cm}$ a $82 \mathrm{~cm}$ até o ano de 2100 .

Levando em consideração essa gama de questões, a elaboração de políticas públicas de adaptação e redução da vulnerabilidade é cada vez mais primordial, além de ações de mitigação dos impactos ambientais das aglomerações urbanas costeiras. Nesse contexto, a presente pesquisa se insere na temática, ao delimitar o estudo de caso do município de Santos/SP, considerando, também, sua relação com a Região Metropolitana da Baixada Santista (RMBS), da qual ela faz parte como município de maior projeção econômica, tendo em vista os efeitos prováveis da elevação do nível dos oceanos.

Esta pesquisa tem por meta contribuir para a articulação entre pesquisa e sua aplicação no âmbito municipal, de maneira a identificar fatores que dificultam o contato e a cooperação mútua entre pesquisadores e os tomadores de decisão responsáveis por elaborar as políticas públicas. Santos, o município em análise, ocupa papel estratégico na economia nacional e, como tantas outras áreas costeiras, tem passado por forte especulação financeira e deterioração ambiental, que podem ser maximizadas com o advento das mudanças climáticas, em especial, com o aumento do nível do mar. que poderia comprometer até de forma irreversível os aparatos urbanos e aumentar a vulnerabilidade da população, que já é alta em diferentes setores do município, conforme assinalado por Silva e Nunes (2016).

As questões acima expostas integram um estudo proposto por pesquisadores em atendimento a uma chamada internacional acerca de vulnerabilidade costeira, a partir de mudanças climáticas, aprovado no final de 2013. Esse grupo, composto por cientistas de diferentes instituições brasileiras, bem como dos Estados Unidos e do Reino Unido, denomina-se "METROPOLE: An Integrated Framework to Analyze Local Decision Making and Adaptive Capacity to Large-Scale Environmental Change: Community Case Studies in Brazil, UK and the US" (Processo Fapesp 2012/51876-0, Processo Belmont G8MUREFU3 2201-040). 
O projeto Metropole tem por base avaliar como a vulnerabilidade costeira poderia ser ampliada a partir das mudanças climáticas e como articular os resultados dos cenários criados sobre essas modificações e as decisões políticas, que até o momento se resumem, quase em sua totalidade, a aspectos técnicos ou administrativos da questão, e para esse fim foram selecionados três localidades: Selsey, no Reino Unido, Broward County, nos EUA e Santos, no Brasil. O reconhecimento científico e a incorporação nas ações no nível municipal visam, em última instância, reduzir a vulnerabilidade da população santista frente aos fenômenos relacionados às alterações no clima que podem ocorrer nas próximas décadas.

Para cada localidade em estudo foram escolhidos agentes tomadores de decisão que participaram de entrevistas e de aplicação de questionários. A ferramenta Adaptive Capacity Index (Índice de Capacidade Adaptativa - ACI), que se constitui em uma atividade de entrevistas elaborada pelo núcleo de pesquisadores na King's College London, tem por objetivo apreender o arcabouço institucional e as possibilidades para ações individuais que compõem a capacidade de adaptação de cada caso, já que, para esses pesquisadores, atualmente as medidas públicas tomadas se resumem principalmente a mitigação das mudanças climáticas, deixando de lado a adaptação aos efeitos oriundos dessas mudanças no futuro (PELLING et al., 2008).

Sendo contribuinte do Projeto Metropole, a ênfase nesse artigo é a aplicação do ACI no município de Santos, o qual necessita de informações acerca das características socioambientais do local e revisão da base regulatória sobre resiliência costeira e dos planos de adaptação do município. Essa ferramenta subsidiará as discussões finais no que concerne à maior articulação entre os cenários de mudanças climáticas criados, com ênfase na elevação do nível do mar, e as medidas aplicadas pelos tomadores de decisão.

\section{Santos em face do desafio da adaptação às mudanças do clima}

A Baixada Santista, como é conhecida a região onde se localiza o município de Santos, está situada no litoral central do estado de São Paulo e representa um setor isolado na forma de baixada, com morros isolados entre a Serra do Mar e o oceano (ZUNDT, 2006). O município se divide entre uma área insular de $39,4 \mathrm{~km}^{2}$ e uma porção continental de 231,6 km². Conforme explica Afonso (2006), devido à proximidade entre as porções insular e continental formam-se grandes estuários naturais de canais estreitos e profundos.

De acordo com os dados do Censo de 2010 (IBGE, 2010), o município de Santos é o mais populoso da Baixada Santista, com quase 420 mil habitantes. Esse município integra a Região Metropolitana da Baixada Santista (RMBS), que ocupa área de $2.818 \mathrm{~km}^{2}$, da qual fazem parte mais oito municípios: Bertioga, Cubatão, Guarujá, Itanhaém, Mongaguá, Peruíbe, Praia Grande e São Vicente, totalizando mais 
de 1,6 milhão de habitantes. Devido a sua vocação turística a área convive com uma população flutuante expressiva, podendo mais do que dobrar nas altas temporadas. Apresenta elevado grau de urbanização (acima de 97\%) e adensamento populacional, sendo que 67\% de seu território é vegetado.

Volumes de chuva altos ao longo do ano, e mesmo entre as estações sazonais a diferença de distribuição não é tão acentuada como em outros setores do estado de São Paulo, demonstrando que os mecanismos produtores de precipitação são distintos de áreas mais continentais (NUNES, 1997). Esse setor registra constantemente sistemas frontais, brisas marítimas e atuação da Zona de Convergência do Atlântico Sul, principalmente no verão, assim como precipitação local intensificada em alguns pontos pelo efeito orográfico. As temperaturas são constantemente altas, e tudo isso faz com que a área seja naturalmente frágil e instável, já que sofre forte atuação do intemperismo químico.

As singularidades da área em relação às suas características físicasforam determinantes no processo de urbanização local e desenvolvimento econômico da região, assim como no surgimento de áreas suscetíveis e populações vulneráveis. Sendo uma das áreas de ocupação mais antigas do país, seu ambiente tem sido alterado há vários séculos, impactando de forma significativa suas características naturais originais.

Atualmente a região possui vocação díspar em relação ao seu potencial econômico (porto e polo industrial de grande porte e vocação turística) que se mesclam a reservas ambientais e áreas de proteção legal, denotando extrema complexidade em suas relações espaciais (ZUNDT, 2006), fato evidenciado pela intensa urbanização que tem alterado significativamente o ambiente físico, sendo que a conservação das áreas naturais próximas às áreas urbanizadas continua sendo considerada pouco importante. Young (2009) enfatiza que a falta de conservação das áreas naturais na RMBS é observada a partir dos processos de degradação ambiental e dos impactos relacionados às atividades urbanas.

Inúmeros são os problemas enfrentados na Baixada, setor que mesmo sem maiores intervenções se caracteriza como um ambiente instável. Contudo, inúmeras ações antropogênicas contribuem para o aumento desses problemas: os manguezais e as águas dos estuários são contaminados pelos efluentes das indústrias pesadas localizadas em Cubatão, enquanto os gases tóxicos lançados pelas indústrias promovem processos erosivos nas encostas das serras de forma indireta, ao contribuir para a perda da vegetação; o desmatamento contínuo para a expansão da malha urbana; as características das áreas próximas ao mar já foram quase totalmente modificadas, perdendo as áreas originais de dunas e de depressões alagadas; poluição do solo e água por efluentes e resíduos sólidos urbanos; ocupações em locais irregulares que impactam as características locais do solo ou que aumentam a vulnerabilidade da população em relação a fenômenos como inundações ou escorregamentos, entre outros (YOUNG, 2009). 
Santos não tem legislação municipal para adaptação às mudanças no clima, mas é governada por uma série de leis nacionais e estaduais. O Estado de São Paulo foi um dos primeiros a adotar uma política de mudança climática em 1995 e 2009. A lei federal afirma que o financiamento de projetos devetrazer benefícios em longo prazo, incluindo ganho social e econômico (KRELLENBERG et al., 2014). Em 2015, Santos criou uma Comissão Municipal de Adaptação às Mudanças Climáticas para o desenvolvimento do Plano Municipal de Adaptação às Mudanças Climáticas, consequência direta do Projeto Metropole.

Tais fatos ilustram aspectos bastante contemporâneos e generalizados que caracterizam a ocupação urbana costeira: de um lado rapidez e a falta de planejamento com a qual ela se opera, com grande alteração do ambiente físico; de outro, a dificuldade das políticas públicas em operar na mesma velocidade e de forma eficaz, o que faz com que os desafios para o planejamento de políticas públicas socioambientais sejam significativos na RMBS, ainda mais se forem levados em consideração os aspectos das mudanças climáticas. Tudo isso assinala que a associação entre as pesquisas científicas e as políticas públicas é cada vez mais fundamental, especialmente quando se testemunha a dificuldade existente em se atrelar esses dois campos, o que resulta, entre outros problemas, em políticas que não levam em consideração estudos sobre as mudanças ambientais, em especial, do clima.

\section{ACI}

\subsection{Metodologia}

Embora seja fácil apontar para um conjunto de iniciativas e ações de gestão de risco, políticas de clima e de resiliência que estão em curso no estado de São Paulo, bem como no cenário político nacional, a compreensão da capacidade adaptativa dos atores envolvidos nessas questões é chave para gerar uma imagem do potencial sucesso da adaptação regional. A capacidade dos governos locais em implementar tais políticas e das organizações públicas e privadas em criar oportunidades para a adaptação está diretamente ligada à capacidade adaptativa desse ator. Portanto, compreender as possíveis limitações e barreiras na escala das organizações e das agências também é fundamental especialmente se tem sido argumentado que esta é a escala em que as respostas da sociedade aos impactos relacionados ao clima serão conduzidas e implementadas (BERKHOUT, 2012; EISENACK et al., 2014).

A pesquisa tem por base a aplicação do Índice de Capacidade Adaptativa (PELLING; ZAIDI, 2013) que é uma atividade de entrevistas que tem por objetivo facilitar uma melhor relação entre as informações disponíveis por pesquisas, modelos e cenários realizados pelo campo científico, com as autoridades tomadoras de decisão, que podem basear-se nessa ferramenta para a elaboração de políticas públicas. Para isso, é necessário levantamento de dados de diversas naturezas que caracterizem a área de estudo e sua 


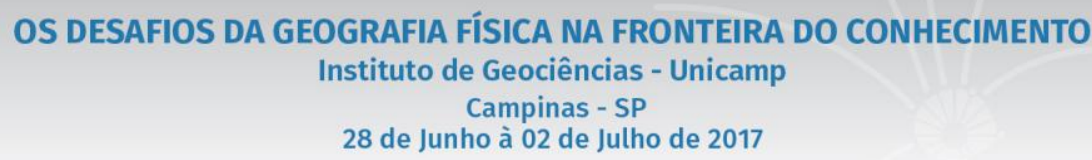

dinâmica socioespacial e revisão bibliográfica sobre diversos aspectos a serem contemplados no estudo, como mudanças climáticas e outras informações sobre a RMBS, que dão suporte à aplicação dessa ferramenta.

A metodologia do ACI consiste em: 1) estruturação da ferramenta em torno de qualidades gerais da capacidade adaptativa derivada da teoria; 2) confirmação das categorias de relevância local por meio da discussão inicial com um pequeno grupo de entrevistados; 3) implantação da ferramenta; e 4) apresentação dos resultados a um grupo de entrevistados e possibilitar a oportunidade de verificação, desafio e divulgação.

A análise do ACI para o município de Santos foi realizada a partir de entrevistas com uma amostra de 24 especialistas e representantes de diferentes instituições e organizações que atualmente povoam a arena do gerenciamento de risco ambiental e das mudanças climáticas em Santos, conforme Tabela I. Por conseguinte, este índice reflete o desempenho de redução de risco relacionado ao clima e adaptação com base nas avaliações de acadêmicos, profissionais e oficiais da região. As 24 entrevistas foram realizadas no município de Santos e via Skype, com duração em torno de uma hora cada, entre os dias 20/10/2015 e 17/02/2016.

O ACI é derivado de uma série de entrevistas semiestruturadas realizadas pessoalmente com as principais partes interessadas. As entrevistas normalmente duram cerca de uma hora, durante as quais se pede aos entrevistados que atribuam um valor de desempenho em uma escala de cinco pontos (Muito limitado, Básico, Razoável, Acima da média, Ótimo) para três anos (2005, 2010 e 2015, determinados anteriormente para melhor visualização da evolução de cada tema na década anterior, permitindo aos entrevistados lembrar como era a situação nos anos anteriores, indicando ações concretas nesse sentido, assim como possíveis resultados de tais ações) a cada indicador e discutam as condições que moldaram sua capacidade e a da organização no gerenciamento de risco ambiental. Esta combinação de métodos qualitativos e quantitativos proporciona uma maior contextualização e clareza e atua tanto para validar com os exemplos fornecidos como para destacar potenciais recomendações de políticas.

Os resultados para 2005, 2010 e 2015 são apresentados inicialmente nas pontuações globais dos subcomponentes de capacidade adaptativa (Tabela II) e foram desagregados por escala e setor em análises adicionais quando apropriado. Os resultados globais do ACI para Santos mostram uma tendência persistente de progressão nos últimos dez anos (Figura 1). 
Tabela I - Organizações participantes do ACI em Santos/SP.

\begin{tabular}{|c|c|c|c|c|c|c|c|c|c|}
\hline \multirow{2}{*}{\multicolumn{2}{|c|}{$\underline{\text { Santos/SP }}$}} & \multicolumn{8}{|c|}{ FUNÇÃO } \\
\hline & & $\begin{array}{c}\text { Uso da } \\
\text { terra/Planejamento/ } \\
\text { Administração }\end{array}$ & $\begin{array}{c}\text { Meio } \\
\text { Ambiente }\end{array}$ & $\begin{array}{c}\text { Emergência e } \\
\text { gerenciamento } \\
\text { de risco }\end{array}$ & Transporte & $\begin{array}{c}\text { Energia e } \\
\text { Água }\end{array}$ & Economia & $\begin{array}{c}\text { Estrutura } \\
\text { social }\end{array}$ & Saúde \\
\hline \multirow{3}{*}{ 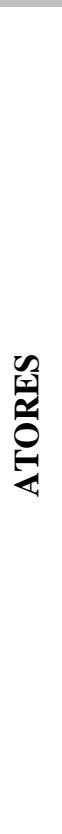 } & $\begin{array}{l}\text { Governo (local, } \\
\text { regional, } \\
\text { estadual e } \\
\text { federal) }\end{array}$ & $\begin{array}{c}\text { i. Agência } \\
\text { Metropolitana da } \\
\text { Baixada Santista } \\
\text { (AGEM) } \\
\text { ii. Unidade de gestão do } \\
\text { programa Santos Novos } \\
\text { Tempos (UGP) } \\
\text { iii. Secretaria do } \\
\text { desenvolvimento urbano }\end{array}$ & $\begin{array}{l}\text { i. Secretaria do } \\
\text { meio ambiente } \\
\text { ii. Instituto de } \\
\text { pesca }\end{array}$ & $\begin{array}{l}\text { i. Defesa civil de } \\
\text { Santos } \\
\text { ii. Corpo de } \\
\text { bombeiros }\end{array}$ & $\begin{array}{l}\text { i. Companhia } \\
\text { de } \\
\text { Engenharia } \\
\text { de Tráfego } \\
\text { (CET- } \\
\text { Santos) } \\
\text { ii. } \\
\text { Companhia } \\
\text { Docas do } \\
\text { Estado de } \\
\text { São Paulo } \\
\text { (CODESP) }\end{array}$ & & & $\begin{array}{c}\text { i. } \\
\text { Secretaria } \\
\text { do Turismo } \\
\text { ii. } \\
\text { Secretaria } \\
\text { da Cultura }\end{array}$ & $\begin{array}{l}\text { i. Secretaria de } \\
\text { saúde } \\
\text { ii. } \\
\text { Departamento } \\
\text { de vigilância } \\
\text { em saúde } \\
\text { (DEVIG) }\end{array}$ \\
\hline & Sociedade civil & & $\begin{array}{l}\text { i. Instituto } \\
\text { Ecofaxinaii. } \\
\text { Instituto Mar } \\
\text { Azul } \\
\text { iii. Instituto } \\
\text { Maramar }\end{array}$ & & & & $\begin{array}{c}\text { i. Associação } \\
\text { dos } \\
\text { Empresários } \\
\text { da } \\
\text { Construção } \\
\text { Civil da } \\
\text { Baixada } \\
\text { Santista } \\
\text { (ASSECOB) }\end{array}$ & $\begin{array}{l}\text { i. Fórum da } \\
\text { Cidadania } \\
\text { ii. OAB }\end{array}$ & \\
\hline & Setor privado & & i. Sinergética & & & i. CPFL & $\begin{array}{l}\text { i. Grupo } \\
\text { Mendes }\end{array}$ & $\begin{array}{l}\text { i. SESI } \\
\text { ii. SESC }\end{array}$ & \\
\hline
\end{tabular}


Tabela II - Pontuações globais dos subcomponentes de capacidade adaptativa de Santos/SP.

\begin{tabular}{cccc}
\hline & $\mathbf{2 0 0 5}$ & $\mathbf{2 0 1 0}$ & $\mathbf{2 0 1 5}$ \\
\hline Autorreflexãocrítica & $\mathbf{3 , 0 3}$ & $\mathbf{3 , 1 4}$ & $\mathbf{3 , 4 1}$ \\
\hline Capacidade de experimentar & $\mathbf{2 , 6 9}$ & $\mathbf{2 , 6 9}$ & $\mathbf{2 , 9 4}$ \\
Capacidade de aprender & $\mathbf{2 , 9 1}$ & $\mathbf{3 , 1 2}$ & $\mathbf{3 , 4 1}$ \\
$\begin{array}{c}\text { Capacidade para planejar para o } \\
\text { futuro }\end{array}$ & $\mathbf{2 , 9 9}$ & $\mathbf{3 , 1 7}$ & $\mathbf{3 , 4 3}$ \\
$\begin{array}{c}\text { Comando com os recursos } \\
\text { disponíveis }\end{array}$ & $\mathbf{2 , 3 7}$ & $\mathbf{2 , 5 9}$ & $\mathbf{3 , 0 1}$ \\
$\begin{array}{c}\text { Responsabilidadeorganizacional } \\
\text { Arquiteturaorganizacional }\end{array}$ & $\mathbf{3 , 1 1}$ & $\mathbf{3 , 3 3}$ & $\mathbf{3 , 6 1}$ \\
Níveis de capital & $\mathbf{2 , 7 7}$ & $\mathbf{2 , 9 1}$ & $\mathbf{3 , 1 8}$ \\
\hline & & $\mathbf{3 , 1 9}$ & $\mathbf{3 , 4 0}$ \\
\hline
\end{tabular}

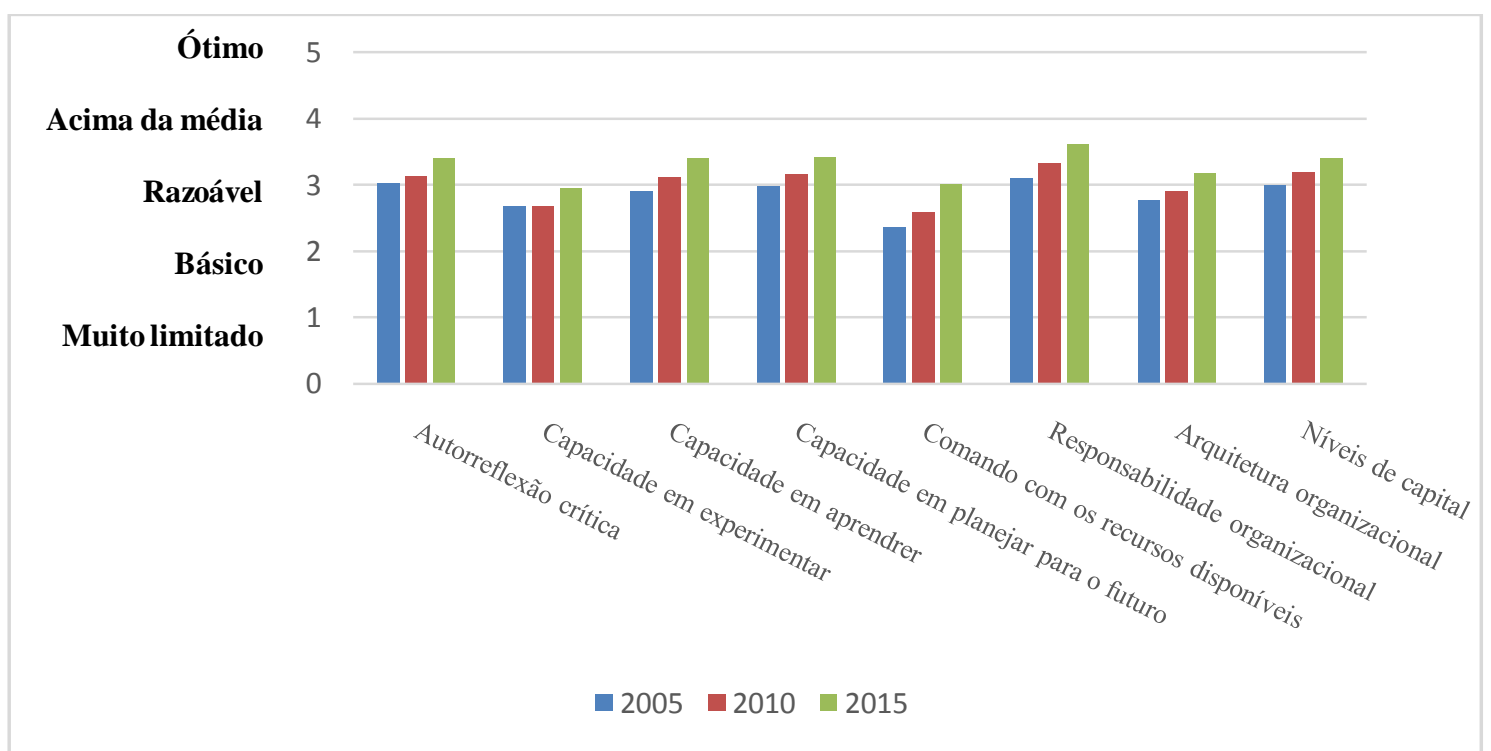

Figura 1 - Resultados gerais do ACI em Santos/SP.

\subsection{Resultados}

Santos demonstrou aumentos consistentes e progressivos na capacidade de adaptação entre 2005 e 2015. Embora os entrevistados tenham indicado índices altos, mais próximos do ótimo (forte capacidade formal com planejamento integrado e estratégico entre setores) em muitos componentes, a distância entre as condições antigas e atuais não foram significativas.

A falta de progressão nas componentes do ACI na perspectiva dos atores locais foi explicada por: i) falta de integração organizacional no regime de gestão de riscos; e ii) domínio da agenda de adaptação pela Defesa Civil. Isso suprimiu incentivos para liderança e inovação, especialmente entre múltiplas agências. Pressões econômicas globais também foram sentidas por Santos. Enquanto a recessão econômica global de 2008 teve um efeito limitado sobre a economia brasileira na época, maiores impactos foram observados após 2014 , com recursos mais restritos e oportunidades de financiamento 
relatadas em todos os setores e agências. Juntas, essas pressões serviram para estabilizar a capacidade de adaptação de Santos.

Algumas das principais conclusões foram listadas para juntar todas as informações coletadas nas entrevistas para este artigo: i) recursos financeiros limitados e os complexos sistemas administrativos que impedem a aprovação de novos projetos e, portanto, a aquisição de recursos em diferentes fontes de recursos; ii) definição de atribuição da questão de gestão de risco dentro das organizações/ falta de reconhecimento da questão, iii) falta de apoio do setor público aos outros setores, e iv) necessidade de integração das organizações para melhor planejamento e ação na área, o que também é afetado pela falta de continuidade das diferentes administrações.

O setor civil de Santos, ao mesmo tempo expressou a existência de altos níveis de capacidade adaptativa, ao descrever sua estrutura organizacional e destacar que havia recursos suficientes para atuar na área do gerenciamento de risco, mas também evidenciou a restrição da legislação, a reestruturação das agências governamentais e a falta de integração em todo o regime de gestão de risco, além de dificuldade de iniciar novos experimentos na área e aprendizagem para adaptação.

O setor privado expressou altos níveis de capacidade adaptativa em muitos componentes, com exceção do "comando sobre os recursos disponíveis". Isso sugere que a capacidade de adaptação e a agenda de desenvolvimento em Santos são muito mais impulsionadas pelo setor privado do que pelo setor civil ou governamental. A privatização ou contratação de serviços anteriormente municipais resultou em uma comunicação fragmentada entre diferentes agências, empresas de serviços públicos e administração municipal, reduzindo a capacidade municipal para lidar com os efeitos das mudanças climáticas.

As agências governamentais demonstraram altos níveis de capacidade adaptativa, com uma mudança limitada ou inexistente ao longo do tempo. Isso provavelmente reflete que tais agências demoraram a demonstrar mudanças ao longo do tempo devido às estruturas estáveis e rígidas. O governo regional demonstrou mudanças limitadas na capacidade adaptativa ao longo do tempo com a maior mudança no nível da cidade. Os entrevistados associaram esses aumentos, especialmente para o período de 20102015, a um extenso investimento em gestão de risco e adaptação em resposta a grandes eventos de desastres ocorridos no país entre 2008 e 2011. Impulsionadas por novas leis e diretrizes, ocorreram mudanças em várias organizações centrais, particularmente na Defesa Civil, o que abriu espaço político e burocrático para a mudança organizacional.

O domínio de um único ator do setor público - a Defesa Civil - na concepção, institucionalização e implementação da política formal de adaptação teve um efeito limitador. Isso se refletiu na falta de reconhecimento das questões de mudança climática por parte de outras organizações em todo o regime de gerenciamento de riscos e na limitada integração entre a Defesa Civil e outros setores. A falta de 
uma participação mais abrangente no ambiente de risco e adaptação ao problema de adaptação e apropriação parece restringir a capacidade adaptativa na cidade, fazendo com que as organizações permaneçam estáticas diante dos riscos emergentes, com raras exceções.

A falta de recursos financeiros foi identificada na maioria das entrevistas como uma barreira à gestão de riscos, especialmente devido à falta de flexibilidade e ao lento desembolso de recursos para a cidade de órgãos estaduais e do governo federal. A burocracia tem sido identificada como um pontochave para a redução da capacidade de adaptação do município, uma vez que os atores do cenário de gerenciamento de riscos optam por não usar seu tempo ou recursos para desenvolver pedidos de financiamento para projetos de adaptação devido ao peso de fazê-lo. Isso limitou a experimentação dentro da cidade e dentro de organizações-chave, afetando negativamente a capacidade de adaptação e reduzindo as possibilidades de reforçar elementos centrais da infraestrutura da cidade.

Enquanto o uso do "shadow space", que em uma tradução livre pode ser entendido como estruturas de governança que não contam com uma formalização oficial, mas que podem ser efetivas por serem mais ágeis foi consistentemente considerado como "a norma", em Santos se destacaram limitações causadas pela reestruturação regular e modificação das descrições de cargos e responsabilidades dentro das agências governamentais, o que criou sentimentos de um ambiente social instável prevalecente, tanto em termos de estabilidade do emprego e estrutura organizacional e sentimentos de isolamento e desconexão dentro e entre níveis hierárquicos. Quando essas relações não oficiais ("shadow space") foram deixadas de lado e as principais comunicações internas das organizações tinham sido reduzidas a relações formais, o diálogo entre organizações foi percebido como mais lento e menos eficaz. Com confiança na rede formal limitada, especialmente localmente, e capacidade local considerada quase inexistente por organizações de ordem superior, o shadow space continua a ser vital para encaminhar a agenda de adaptação em todo o setor de risco. No entanto, a instabilidade percebida e a natureza dinâmica dos cargos oficiais de conselhos e agências nacionais significa que esse setor já fraturado se torna ainda mais difícil de operar.

O shadow space é frequentemente considerado demasiado complexo para ser explorado em muitos contextos políticos e de gestão e regularmente visto como uma fonte de corrupção e ineficiência que requer maior gestão e controle (HIGH et al., 2004). Porém, este estudo de caso demonstra o oposto, já que o shadow space é parte responsável por uma grande mudança na capacidade organizacional e governamental resultando em potencial de mudança positivo em Santos. 


\section{Consideraçõesfinais}

A análise do ACI de organizações envolvidas na gestão de riscos ambientais em Santos e seus principais influenciadores em escalas superiores indicam algumas áreas onde o movimento positivo pode ser aprimorado para que os ganhos demonstrados na última década aproveitem a incorporação das lições apreendidas como a avaliação da capacidade adaptativa. A partir desta base, muitas das opções para maior capacidade de adaptação que se preocupam com a aprendizagem, a informação, a devolução de responsabilidades e as redes podem ser abordadas. Resumindo a análise do ACI indica cinco recomendações principais que podem ser feitas:

1. Maior conectividade - e compreensão - entre os esforços e atividades locais motivados por preocupações setoriais e locais específicas e a estrutura de planejamento e desenvolvimento de gestão de riscos da cidade;

2. Aumento da transparência dos processos de tomada de decisão em escalas superiores para elevar os níveis de conhecimento e percepção da problemática pela sociedade e instituições;

3. Melhorar as relações formais/estrutura organizacional para fornecer um mecanismo de colaboração;

4. Promover uma propriedade e liderança da questão para além da Defesa Civil;

5. Desenvolvimento de uma parceria voluntária e cooperativa entre os órgãos governamentais locais como um mecanismo para aliviar os impactos da descentralização de responsabilidade sem recursos, questão que muitas vezes impacta os esforços de adaptação, e que pode ser usado como um modelo potencial para a Comissão Municipal de Adaptação às Alterações Climáticas.

O desafio de lidar com os impactos climáticos futuros, que muitas vezes ainda não foram experimentados, é agravado pelos níveis de risco associados à incerteza que os países, governos, organizações, comunidades e indivíduos devem lidar e tentar tirar vantagem. À medida que as alterações climáticas se intensificam e aceleram, a capacidade de lidar com os impactos e a capacidade em se adaptar às oportunidades serão atributos críticos. Isso significa que qualquer pessoa em um papel que requer decisões duradouras potencialmente afetadas pelo clima, a maioria das quais não será especialista em adaptação ou especialista em clima, idealmente teria conhecimento dos níveis de capacidade de adaptação existente dentro de sua organização, bem como área com potencial de desenvolvimento.

A adaptação envolve o controle e o aperfeiçoamento de sistemas sociotecnicos (pessoas e bens) para que os sistemas acoplados possam ser mais bem preparados para as mudanças climáticas, como a elevação do nível do mar e a frequência e intensidade de inundações e eventos de tempestade. Isso significa que são necessárias mudanças no comportamento social em conjunto com a mudança de 
infraestrutura. No entanto, as modificações à infraestrutura são normalmente difíceis de serem realizadas, com oportunidades raras para fazê-las de uma forma rentável. No caso de uma barreira de proteção do mar de 50 anos de vida útil, por exemplo, pode haver alterações durante seu processo de concepção e construção; porém, uma vez que ela tenha sido construída, muitas das suas características tornam-se muito difíceis e por vezes impossíveis de alterar (por exemplo: sua localização física, materiais utilizados, estruturas de drenagem etc.). Isso mostra porque a mudança é um desafio: as oportunidades ocorrem raramente e quando o fazem, a despesa é geralmente altamente restritiva. Em geral, é muito mais fácil e mais barato se adaptar quando as decisões são tomadas em vez de corrigilas mais tarde. Isto implica que, se a capacidade é baixa, mas decisões importantes são esperadas, então concentrar esforços na melhoria dos resultados para o máximo retorno sobre o investimento é fundamental. Por outro lado, um alto nível de capacidade adaptativa permite que os tomadores de decisão dentro de seus próprios setores concebam e implementem estratégias de adaptação às mudanças climáticas na sua própria esfera de influência e contribuam para ampliar os esforços em todo o cenário de governança de risco. Além disso, quando a capacidade é alta, mas não são esperadas decisões, isso fornece uma fonte de aprendizado ou pessoas capacitadas que podem potencialmente ser usadas para apoiar outras pessoas a desenvolver sua própria capacidade.

O ACI foi concebido para permitir a geração de soluções identificadas por atores, resultando em uma abordagem mais proativa de como as questões de mudança climática são abordadas. Por meio da inclusão de mecanismos de aprendizagem social e da capacitação de atores, o ACI baseia-se nos esforços existentes para medir a capacidade adaptativa, combinando dados quantitativos e qualitativos. Desenvolver a capacidade de adaptação para ser capaz de realmente implementar ações de adaptação é um processo de ajuste contínuo em resposta a uma série de questões, portanto, é importante ser realista em termos de expectativas ao considerar o potencial de qualquer quadro para inspirar a mudança de comportamento, especialmente no curto prazo. No entanto, a provisão do espaço para o discurso e a avaliação continua a ser um dos caminhos mais essenciais para o sucesso e um objetivo fundamental desta ferramenta. Cada estudo de caso adicional pode demonstrar a utilidade de não apenas medir a capacidade de adaptação, mas como usar essa análise pode capacitar a tomada de decisão orientada à adaptação e proporcionar a oportunidade de reorientar a gestão para uma base mais proativa, bem como desenvolver novas oportunidades de aprendizagem para os atores.

O estudo de caso de Santos gera uma série de recomendações e "insights" em relação à capacidade adaptativa. No entanto, a capacidade dos atores locais é, em muitos aspectos, moldada por suas relações e interdependências com o cenário de governança mais amplo: principalmente o contexto político e econômico em que devem operar (HIGH et al., 2004). Grande parte da interação entre os atores locais e os diversos setores ocorre dentro do "shadowspace", das relações informais e pessoais que encarnam a vida pública e privada, ao invés de caminhos organizacionais regulares (PELLING et 
al., 2008). Isso se torna ainda mais importante para Santos devido às mudanças de governos que dificultam a continuidade das políticas locais e deve ser encorajado a manter e aumentar a capacidade de adaptação do município.

\section{Agradecimento}

Pesquisa realizada com financiamento da Fundação de Amparo à Pesquisa do Estado de São Paulo (Proc. Fapesp 2014/14598-8), projeto Metropole (Proc. Fapesp 2012/51876-0). Agradecimento aos inúmeros entrevistados, que deram parte de seu tempo para responder ao questionário do ACI.

\section{Referênciasbibliográficas}

AFONSO, C. M. A paisagem da Baixada Santista: urbanização, transformação e conservação. São Paulo: Edusp. Fapesp, 2006

BERKHOUT, F. Adaptation to climate change by organizations. Wiley Interdisciplinary Reviews: Climate Change, 2012. 3, 91-106

CARMO, R. L. do; SILVA, C. A. M. da. População em zonas costeiras e mudanças climáticas: redistribuição espacial e riscos. In: HOGAN, D. J.; MARANDOLA JR., E. (Org.). População e mudança climática: dimensões humanas das mudanças ambientais globais. Campinas: Núcleo de Estudos de População - Nepo. Unicamp; Brasília: UNFPA, 2009

EISENACK, K. et al. Explaining and overcoming barriers to climate change adaptation. Nature Clim.Change, 2014. 4, 867-872

HIGH, C. et al. Local agency, adaptation and the shadow system: The institutional architecture of social learning in rural areas of the UK and India. XI World Congresson Rural Sociology, 25-30 July 2004. Trondheim, Norway, 2004

IBGE - Instituto Brasileiro de Geografia e Estatística. Censo 2010. 2010

IPCC - Intergovernmental Panel on Climate Change.Climate Change 2007: Synthesis Report. Contribution of Working Groups I, II and III to the Fourth Assessment Report of the Intergovernmental Panel on Climate Change. IPCC, Geneva, Switzerland, 2007

Climate change 2013: The Physical Science Basis. Contribution of Working Group I to the Fifth Assessment Report of the Intergovernmental Panel on Climate Change. Cambridge University Press, Cambridge, United Kingdom and New York, NY, USA, 2013

KRELlEnBERG, K. et al. Adaptation to Climate Change in Megacities of Latin America: Regional Learning Network of the research project ClimateAdaptationSantiago (CAS) Santiago, Chile.EconomicCommission for LatinAmericaandtheCaribbean (ECLAC), 2014

NUNES, L.H. Distribuição espaço-temporal da pluviosidade no Estado de São Paulo: tendências, variabilidade, processos intervenientes, 1997, EPUSP, 197p.

PELLING, M. et al. Shadow spaces for social learning: a relational understanding of adaptive capacity to climate change within organisations. Environment and Planning A, 40, 867-884, 2008

PELLING, M.; ZAIDI, R. Z. Measuring adaptive capacity: application of an indexing methodology in Guyana. EPD Working Paper \#47, Department of Geography, King's College London, 2013

SILVA, R.B. da, NUNES, L.H. Vulnerability profiles in a Metropolitan Area of Brazil. Saarsbrüchen: Lambert AcademicPublishing, 97 p. 2016; 
YOUNG, A. F. Mudanças climáticas: entre a coesão e a fragmentação dos assentamentos humanos, os conflitos e as transformações da paisagem na Baixada Santista. In: HOGAN, D. J.; MARANDOLA JR., E. (Org.). População e mudança climática: dimensões humanas das mudanças ambientais globais. Campinas: Núcleo de Estudos de População - Nepo. Unicamp; Brasília: UNFPA, 2009;

ZUNDT, C. Baixada Santista: uso, expansão e ocupação do solo, estruturação de rede urbana regional e metropolização. In: CUNHA, J. M. P. da. Novas Metrópoles Paulistas: População, vulnerabilidade e segregação. Campinas: Núcleo de Estudos de População - Nepo. Unicamp, 2006. 